\title{
Experience of nurse practitioners performing colonoscopy after endoscopic training in more than 1,000 patients
}

\section{다)(우우}

\author{
Authors \\ Monica Riegert ${ }^{1}$, Monica Nandwani ${ }^{2}$, Bonny Thul ${ }^{3}$, Angela Chang Chiu ${ }^{1}$, Simon C. Mathews ${ }^{4}$, Mouen A. Khashab ${ }^{1}$, \\ Anthony Nicholas Kalloo ${ }^{1}$
}

Institutions

1 The Johns Hopkins Hospital, Division of Gastroenterology and Hepatology, Baltimore, Maryland, United States

2 Stanford Health Care, Center for Advanced Practice, Division of Gastroenterology and Hepatology, Stanford, California, United States

3 Winona Health, Winina, Minnesota, United States

4 Johns Hopkins Medicine Armstrong Institute for Patient Safety and Quality, Baltimore, Maryland, United States

submitted 28.2.2020

accepted after revision 24.6.2020

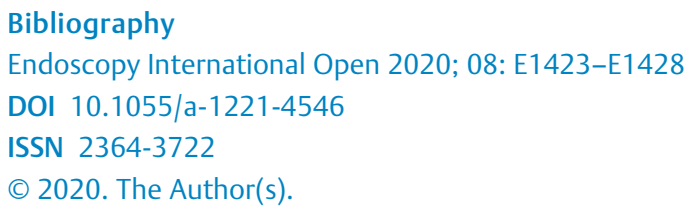

This is an open access article published by Thieme under the terms of the Creative Commons Attribution-NonDerivative-NonCommercial License, permitting copying and reproduction so long as the original work is given appropriate credit. Contents may not be used for commecial purposes, or adapted, remixed, transformed or built upon. (https://creativecommons.org/licenses/by-nc-nd/4.0/)

Corresponding author

Monica Riegert, DNP, CRNP, The Johns Hopkins Hospital, Division of Gastroenterology and Hepatology, 4940 Eastern Avenue, A-5 East, Baltimore, MD 21224

Fax: +1-410-550-7861

mrieger2@jhmi.edu

\section{ABSTRACT}

Background and study aims The demand for screening colonoscopy has continued to rise over the past two decades. As a result, the current workforce of gastroenterologists is unable to meet the needs for colorectal cancer (CRC) screening. Therefore, solutions are needed to improve this disparity, with non-physician endoscopists being a potential option. However, current literature on the performance of non-physicians in endoscopy is limited. The aim of this study was to assess the quality of colonoscopy performed by three gastrointestinal fellowship-trained nurse practitioners (NPs).

Methods This was a retrospective study performed at a single tertiary academic medical center. Colonoscopies performed by three gastrointestinal-specialized NPs after having completed training of at least 140 supervised colonoscopies were reviewed for analysis. Inclusion criteria were patients undergoing colonoscopy for colorectal cancer screening purposes. Outcomes included colonoscopy quality indicators as defined by the American Society for Gastrointestinal Endoscopy/American College of Gastroenterology Taskforce (ASGE/ACG) Taskforce.

Results The study included 1,012 subjects (mean age 56.2 years, female $51.5 \%$, African American $73.9 \%$ ) who underwent screening colonoscopies by three NPs. Cecal intubation was successful in 997 subjects (98.5\%). Mean adenoma detection rate was $35.6 \%$. Mean withdrawal time was 18.9 minutes. There were no adverse events including colonic perforations or delayed post-polypectomy bleeding.

Conclusions Three fellowship-trained NPs in colonoscopy in the United States satisfied the quality indicators proposed by the ASGE/ACG Task force, demonstrating that adequately trained NPs can perform colonoscopy safely and effectively. With the demand for colonoscopy exceeding the supply, non-physicians could be part of the solution to meet the demands for CRC screening.

\section{Introduction}

As the third leading cause of cancer-related deaths in both men and women in the United States, colorectal cancer (CRC) is a significant health concern [1]. In 2018, there were over
140,000 estimated new cases of CRC and over 50,000 CRC related deaths, with an overall lifetime risk of $4 \%$ to $5 \%$ [1]. Fortunately, CRC incidence and mortality rates have been steadily declining over the past 30 years, primarily due to increased 
screening rates but also in part due to advances in screening. Colonoscopy is currently considered the preferred screening test, especially for high risk individuals, with studies showing colonoscopy reduces CRC incidence by $40 \%$ and mortality by $50 \%$ to $60 \%[2-4]$.

Use of colonoscopy has steadily increased over the past decade, becoming the most commonly used test for CRC screening in the United States $[5,6]$. There is concern about whether there are adequate resources to meet the need for CRC screening, with several predictive models showing a shortage of gastroenterologists [6-9]. In addition, with total US healthcare costs exceeding $\$ 3.5$ trillion annually, there is increasing focus on providing high-value care [10-11]. Therefore, innovative solutions are needed in gastroenterology both to drive down costs and to bridge the growing gap between supply and demand for colonoscopy. Increasingly, less invasive screening methods are being considered to address these needs. However, another proposed solution is extending endoscopic training to non-physicians, such as nurse practitioners (NPs) [12]. This approach would potentially maintain the diagnostic and therapeutic benefits of colonoscopy at a lower cost while also addressing workforce gaps. This alternative, however, is contingent on the ability of non-physicians to provide adequate and comparable quality colonoscopy to gastroenterologists.

Current literature on the performance of non-physicians in endoscopy is limited, with the majority of studies focused on non-physician performance of flexible sigmoidoscopy. There is evidence to support that non-physicians can perform flexible sigmoidoscopy safely and effectively, with comparable adenoma detection rates (ADRs), adverse events (AEs), and patient satisfaction compared to physicians $[13,14]$. However, much less is known about the performance of non-physicians in colonoscopy. This lack of evidence prompted a 2009 statement by the American Society for Gastrointestinal Endoscopy (ASGE)

- Table1 Fellowship-trained nurse practitioner demographics.

\begin{tabular}{|l|l|}
\hline Characteristics & $\mathbf{N = 3}$ \\
\hline Age (yrs) & 3 \\
\hline - $18-34$ & 0 \\
\hline - $34-60$ & \\
\hline Gender & 3 \\
\hline - Female & 0 \\
\hline - Male & \\
\hline Highest Education & 0 \\
\hline - Bachelor's degree & 2 \\
\hline - Master's degree & 1 \\
\hline - Doctoral degree & \\
\hline Race & 2 \\
\hline - White & 1 \\
\hline - Asian & \\
\hline
\end{tabular}

that "there is insufficient data to support the use of non-physician endoscopists to perform colonoscopy" [15].

The aim of our study was to assess the quality of colonoscopy performed by three fellowship-trained NPs ( $\triangleright$ Table 1 ) after endoscopic training using quality indicators for colonoscopy as defined by the ASGE/American College of Gastroenterology (ASGE/ACG) Taskforce. The three NPs were selected from a pool of candidates who applied for the yearlong nurse practitioner fellowship program. All three of the selected NPs completed the fellowship and remained employed at the same tertiary medical academic center for a minimum of 3 years postfellowship completion.

\section{Methods}

This was a single-center retrospective study analyzing consecutive screening colonoscopies performed by three NPs after completion of endoscopic training. The NPs were trained during a 1-year NP gastroenterology fellowship program, structured with the same didactic and endoscopic training as firstyear medical gastroenterology fellows. Each NP completed a minimum of 140 supervised colonoscopies during training, which is equivalent to the minimum number of colonoscopies recommended by the ASGE to achieve competency [16]. The NPs then underwent a formal performance evaluation to demonstrate competency, including skills of biopsy and polypectomy, before being credentialed and privileged to perform colonoscopy independently within the institution. The first NP successfully completed her endoscopic training in 2010, the second NP in 2011, and the third NP in 2012.

The study was conducted at a large urban outpatient endoscopy center that was part of an academic medical center between September 2010 and June 2016. Inclusion criteria were all patients undergoing colonoscopy for CRC screening purposes. Exclusion criteria were patients undergoing diagnostic colonoscopy and procedures aborted due to an extremely poor bowel preparation. All patients received procedural sedation with the use of either anesthesia-administered propofol or proceduralist-administered fentanyl and midazolam.

Outcome measures included quality indicators for colonoscopy as defined by the ASGE/ACG Taskforce $[17,18]$. The primary outcome was ADR. Secondary outcomes included cecal intubation rate, mean withdrawal time, and complication rates of colonic perforation and post-polypectomy bleeding.

Data collection was performed by review of electronic medical records and endoscopy procedure reports. Data were entered into a secured Excel spreadsheet, from which statistical analysis (mean, range and percentages) was calculated using Excel 2016. Institutional review board (IRB) approval was obtained prior to initiating data collection. Adenoma detection was histologically confirmed. Cecal intubation was verified by photo documentation of cecal landmarks. Withdrawal times were determined using time stamps of cecal images and retroflexion images. Incidence of complications were obtained from procedure report documentation and chart review of any postprocedure hospitalizations. 


\section{Results}

A total of 1,425 colonoscopies were performed by the three NPs during the study period. Of these, 413 colonoscopies were excluded due to indications other than screening $(n=374)$ and procedures aborted due to poor bowel preparation $(n=39)$, resulting in 1,012 colonoscopies included for analysis. Patients had a mean age of 56.2 years (range $41-83$ ), $51.5 \%$ were female, and $73.9 \%$ were African American ( $>$ Table 2 ). Informed consent was obtained from all patients.

NP colonoscopy performance outcomes were compared to the proposed standards for colonoscopy quality indicators recommended by the ASGE/ACG Taskforce ( $\triangleright$ Table 3). Overall, adenomatous polyps were detected in 360 procedures, equating to an overall ADR of $35.6 \%$, with the proposed standard being $\geq 25 \%$. More specifically, the ADR was $39.3 \%$ in males and $32.1 \%$ in females, with the proposed standard being $\geq 30 \%$ males and $\geq 20 \%$ in females. Cecal intubation was successful in 997 subjects ( $98.5 \%$ ), with the proposed standard being $\geq 95 \%$. Procedures where the cecum was not reached was due to excessive looping or angulation based on documentation. If colonoscopies that were aborted due to poor bowel preparation are included in analysis of cecal intubation rate, the number of colonoscopies analyzed would increase to 1,051 and would equate to a $94.9 \%$ success rate. Mean withdrawal time was 18.9 minutes (range $5.8-66.7$ ), with the proposed standard being a mean of $\geq 6$ minutes. There were no complications of colonic perforation or post-polypectomy bleeding, with the proposed standard being $<1: 1000$ perforations for screening colonoscopies and $<1 \%$ incidence of post-polypectomy bleeding. When analyzing NP performance separately, each individual NP also met and exceeded all of the proposed quality standards ( $>$ Table 4 ).

Additional data regarding polyp characteristics and polypectomy technique were also examined ( $\$$ Table 5). In total, 1,471 polyps/lesions were detected. Of these, 847 (57.6\%) were benign, 611 (41.5\%) were adenomas, nine9 (0.6\%) were advanced adenomas, and four $(0.3 \%)$ were adenocarcinomas. Benign polyps included hyperplastic polyps, inflammatory polyps, and non-diagnostic pathology; adenomas included tubular adenomas and sessile serrated adenomas; and advanced adenomas included adenomas with villous features or high-grade dysplasia. The majority of polyps were small, with 1,185 (80.6\%) being 0 to $5 \mathrm{~mm}, 179$ (12.2\%) being 6 to $9 \mathrm{~mm}, 83$ (5.6\%) being 10 to $20 \mathrm{~mm}$, and $24(1.6 \%)$ being $>20 \mathrm{~mm}$. In total, 1,183 polyps $(80.4 \%)$ were removed via cold forceps polypectomy and 276 (18.8\%) were removed via snare polypectomy. Twelve polyps/ lesions $(0.8 \%)$ were not removed, with eight polyps being referred to an advanced therapeutic endoscopist for advanced polypectomy and four polyps not removed because they appeared to be cancerous and not amenable to endoscopic resection.

\section{Discussion}

Overall, the NPs met and exceeded all of the proposed quality ASGE/ACG Taskforce quality standards for colonoscopy, in line with the performance expected by trained physicians. As a re-
Table 2 Patient demographics.

\begin{tabular}{|l|l|}
\hline Characteristics & $\mathbf{N}=\mathbf{1 , 0 1 2}$ \\
\hline Age (yrs) & $56.2 \pm 6.7(41-83)$ \\
\hline Gender & \\
\hline - Female & $521(51.5 \%)$ \\
\hline - Male & $491(48.5 \%)$ \\
\hline Race & \\
\hline - African American & $748(73.9 \%)$ \\
\hline - White & $201(19.9 \%)$ \\
\hline - Asian & $24(2.4 \%)$ \\
\hline - Hispanic & $19(1.9 \%)$ \\
\hline - Other & $20(2.0 \%)$ \\
\hline N= number of procedures & \\
\hline
\end{tabular}

- Table 3 Overall nurse practitioner colonoscopy performance.

\begin{tabular}{|l|l|l|}
\hline $\begin{array}{l}\text { ASGE/ACG Quality } \\
\text { Indicator }\end{array}$ & $\begin{array}{l}\text { NP Outcomes } \\
(\mathbf{N = 1 , 0 1 2 )}\end{array}$ & $\begin{array}{l}\text { Proposed ASGE/ } \\
\text { ACG Standard }\end{array}$ \\
\hline $\begin{array}{l}\text { Adenoma detection rate } \\
\text { - Overall }\end{array}$ & $35.6 \%$ & $\geq 25 \%$ \\
\hline - Male patients & $39.3 \%$ & $\geq 30 \%$ \\
\hline - Female patients & $32.1 \%$ & $\geq 20 \%$ \\
\hline Cecal intubation rate & $98.5 \%$ & $\geq 95 \%$ \\
\hline Withdrawal time & 18.9 min & $\geq 6$ min \\
\hline $\begin{array}{l}\text { Complications } \\
\text { (5.8-66.7) }\end{array}$ & 0 & $\begin{array}{l}\text { Perforation }<1: 1000 \\
\text { Post-polypectomy } \\
\text { bleeding }<1 \%\end{array}$ \\
\hline $\begin{array}{l}\text { ASGE/ACG, American Society for Gastrointestinal } \\
\text { College of Gastroenterology; } \\
\text { N= number nurse practitioner. }\end{array}$ \\
\hline
\end{tabular}

sult, this study demonstrates that adequately trained NPs can perform screening colonoscopy safely and effectively.

Use of screening colonoscopy has continued to rise over the past decade [5]. One major reason for this is increased evidence to support that colonoscopy reduces CRC incidence and mortality, leading to endorsements for screening colonoscopy by all major gastroenterology societies [19]. There has also been increased access to colonoscopy, with Medicare mandating coverage for all beneficiaries in 2001 and private insurers shortly following suit [20]. There has also been a significant rise in the demand for colonoscopy due to the increasing aging population. By 2030, the US population aged 65 and older is projected to grow by $55 \%$, being a large portion of individuals who will require screening [21]. Finally, there has also been an increase in patient awareness efforts, such as the $80 \%$ by 2018 initiative by the National Colorectal Cancer Roundtable (NCCRT), 
- Table4 Individual nurse practitioner colonoscopy performance.

\begin{tabular}{|c|c|c|c|c|}
\hline ASGE/ACG Quality Indicator & $\begin{array}{l}N P \# 1 \\
(N=533)\end{array}$ & $\begin{array}{l}\text { NP \#2 } \\
(N=137)\end{array}$ & $\begin{array}{l}N P \# 3 \\
(N=342)\end{array}$ & Proposed ASGE/ACG Standard \\
\hline \multicolumn{5}{|l|}{ Adenoma detection rate } \\
\hline - Overall & $38.3 \%$ & $44.5 \%$ & $27.8 \%$ & $\geq 25 \%$ \\
\hline - Male patients & $40.9 \%$ & $45.3 \%$ & $34.0 \%$ & $\geq 30 \%$ \\
\hline - Female patients & $35.4 \%$ & $44.1 \%$ & $22.2 \%$ & $\geq 20 \%$ \\
\hline Cecal intubation rate & $98.9 \%$ & $95.6 \%$ & $98.5 \%$ & $\geq 95 \%$ \\
\hline Withdrawal time & $19.6 \min (6.7-66.7)$ & $32.3 \min (7.9-57.3)$ & $12.6 \min (5.8-43.0)$ & $\geq 6 \min$ \\
\hline Complications & 0 & 0 & 0 & $\begin{array}{l}\text { Perforation }<1: 1000 \\
\text { Post-polypectomy bleeding }<1 \%\end{array}$ \\
\hline
\end{tabular}

ASGE/ACG, American Society for Gastrointestinal Endoscopy/American College of Gastroenterology; NP, nurse practitioner. $\mathrm{N}=$ number of procedures

- Table 5 Polyp characteristics and removal technique.

\begin{tabular}{|l|l|}
\hline Polyps/Lesions & $\mathbf{N}=\mathbf{1 , 4 7 1}$ \\
\hline Pathology & \\
\hline - Benign & $847(57.6 \%)$ \\
\hline - Adenomas & $611(41.5 \%)$ \\
\hline - Advanced adenomas & $9(0.6 \%)$ \\
\hline - Adenocarcinoma & $4(0.3 \%)$ \\
\hline Size & \\
\hline - 0 - 5 mm & $1185(80.6 \%)$ \\
\hline - $6-9$ mm & $179(12.2 \%)$ \\
\hline - $10-20$ mm & $83(5.6 \%)$ \\
\hline - >20mm & $24(1.6 \%)$ \\
\hline Polypectomy Technique & \\
\hline - Biopsy & $1183(80.4 \%)$ \\
\hline - Snare & $276(18.8 \%)$ \\
\hline - Not removed & $12(0.8 \%)$ \\
\hline N= number of polyps/lesions & \\
\hline
\end{tabular}

as well as celebrity involvement such as Katie Couric's televised colonoscopy, which were found to effectively boost screening rates [22].

Increased use of colonoscopy raises the question whether there are adequate resources to meet the demand for CRC screening. One study on the projections for demand and capacity for colonoscopy published in 2009 estimated an additional 1,050 gastroenterologists would be needed by 2020 to meet the demands for colonoscopy if screening rates were to remain unchanged, increasing to an additional 1,550 gastroenterologists if screening rates were to increase by $10 \%$ [7]. A similar study published in 2004 estimated that 1,000 additional endos- copists would be needed to meet the demand for colonoscopy if $70 \%$ of the 2004 population were to be screened. Advocacy groups have called for even higher screening rates which would widen this gap. [6]. With the number of trained gastroenterologists having remained steady for the past 30 years and expected to remain unchanged in upcoming years, this increase in the number of gastroenterologists in practice is unlikely to occur [23]. Therefore, training NPs to perform colonoscopy could be a solution to ensure the needs for CRC screening are adequately met.

The role of Advanced Practice Registered Nurses (APRNs), including NPs, has expanded to address the national physician shortage in the United States. Expansion of APRN scope of practice was specifically recommended in the Patient Protection and Affordable Care Act of 2010 to increase health care access and affordability [24]. There are several examples of successful expansion of APRN scope of practice including Certified Registered Nurse Anesthetists (CRNAs) who administer anesthesia services and Certified Nurse Midwives (CNMs) who specialize in ob/gyn, including the delivery of babies. A large systematic review published in 2011 that included 20 randomized controlled trials and 49 observational studies found that APRNs in collaboration with physicians could achieve outcomes and patient satisfaction that were comparable, and in some cases superior, to care by a physician alone [25].

There is precedence for NPs performing colonoscopy in the United Kingdom (UK), where the practice has already been adopted as means to meet the need for increased CRC screening [26]. By 2005, there were approximately 200 NPs performing diagnostic and therapeutic endoscopy procedures, including skills of polypectomy and management of gastrointestinal bleeding [27]. Nurse endoscopists in the UK have demonstrated the ability to perform colonoscopy safely and effectively, with high patient acceptability and improved patient care [27-30]. One UK study analyzing 100 colonoscopies performed by a nurse endoscopist immediately after training found the nurse endoscopist achieved a cecal intubation rate of $92 \%$, with no procedure-related complications and a high de- 
gree of patient satisfaction [27]. The nurse endoscopist also demonstrated competency in polypectomy skills and administration of conscious sedation. A similar subsequent study was conducted in the UK with comparable results, with findings that nurse endoscopists had similar efficacy, safety, and patient satisfaction scores compared to physicians [30]. In 2005, the British Society of Gastroenterology published a position report supporting the use of nonmedical endoscopists to perform endoscopy procedures once they have completed a full training program and are able to demonstrate sufficient knowledge and competence to satisfy established standards [28]. NPs continue to be trained in colonoscopy in the UK, where they have also established strategic guidelines for training and monitoring of non-physician endoscopists [27].

Studies on nurses trained to perform colonoscopy have also been conducted in the Netherlands with results similar to the UK studies. One study at a Dutch center comparing the performance of colonoscopy by two endoscopy nurses, one gastroenterology fellow, and one experienced gastroenterologist, all completing 150 colonoscopies each, found similar cecal intubation rates, time to cecum, and AE rates between groups [31]. Patients also reported similar degrees of pain, levels of satisfaction, and willingness to undergo a future colonoscopy among groups. Additionally, a larger prospective multicenter study performed in the Netherlands analyzing 10 nurse endoscopists performance of 100 consecutive colonoscopies after training found that all of the nurses met the international quality standards with an ADR of $26.7 \%$, average cecal intubation rate of $94 \%$, $\mathrm{AE}$ rate of $0.2 \%$, and high patient satisfaction of $95 \%$ [32].

A Canadian study also demonstrated an NP's ability to perform colonoscopy safely and effectively. The study evaluated 225 independent colonoscopies performed by an NP after completing a 2-year training program and found the NP was as effective as gastroenterologists in performing colonoscopy based on quality measures, with a cecal intubation rate of $92 \%$, polyp detection rate of $39 \%$, and one minor adverse post-polypectomy bleeding event [33].

In the United States, a single-center, randomized controlled trial demonstrated that an NP was able to perform colonoscopy as safely and effectively as her physician colleague. The NP had an $A D R$ of $42 \%$, cecal intubation rate of $100 \%$, mean withdrawal time of 8.5 minutes, and no procedure-related AEs [34]. Another single-center prospective study in the United States evaluating the performance of an NP's first 300 consecutive screening colonoscopies after training found the NP satisfied all of the proposed quality indicators for colonoscopy, with an ADR of $35.0 \%$, cecal intubation rate of $99.0 \%$, mean withdrawal time of 19.3 minutes, and no procedure-related AEs [35].

The results of our study are consistent with previous studies, supporting properly trained NPs as a possible solution to filling the gap between the supply and demand for screening colonoscopies in the United States. CRC screening rates vary widely across the country, with lower screening rates and higher CRCrelated deaths in rural and underserved areas [36]. NPs may be especially useful in these under-resourced settings where conventional access to a gastroenterologist is limited.
Use of NPs performing colonoscopy may also help to reduce overall health care costs. This would result from lower professional fees, reimbursement rates, and salaries compared to physicians. Using the annual salary differential for the same endoscopy case load, we calculated a per-case savings of $\$ 102$. Total savings when multiplied by the number of procedures exceeded $\$ 100,000$ annually. Indirect cost savings have not been calculated, however, having NPs perform colonoscopy can allow gastroenterologists additional time to perform more complex procedures that generate higher revenue. In addition, downstream revenue can be generated for other hospital departments, such as pathology, if more colonoscopies are performed due to the need for additional pathology review. A more robust direct and indirect cost-analysis would be beneficial; however, that was beyond the scope of this paper, which primarily sought to evaluate the quality of fellowship-trained NP colonoscopy when compared to physician colonoscopy.

Limitations of this study are that it focused on a small number of fellowship-trained NPs in a single center. The total number of nurse-endoscopists in the United States at present is unknown and those data are not readily available. In addition, no known complications are reported, however, we cannot rule out complications that may have occurred post-procedure discharge that were unreported by the patients. Of note, patients who underwent biopsy or polypectomy were notified of their pathology results post-procedure and none of the individuals contacted reported complications. A final limitation of this study is that it did not address how many NP colonoscopies required physician support for cecal intubation and/or polypectomy. Future studies providing subjective patient feedback about their experience with a nurse endoscopist may also be of value.

A potential barrier to expanding colonoscopy training to NPs may be a lack of physician acceptance. However, NPs performing colonoscopy may benefit physicians by allowing them to perform more therapeutic and complex cases as discussed above. They may also help to decrease patient wait times and improve overall patient satisfaction which could benefit their overall practice. A more likely scenario is adoption in underserved areas or in large health systems and accountable care organizations where value-based care plays a larger role, however, appropriate training programs would need to be in place in these institutions to support successful NP endoscopic training.

For non-physician endoscopists to effectively scale to meet the supply gaps, colonoscopy training programs with appropriate training guidelines would need to be established. In the setting of our study, three NPs were trained using the same curriculum as first-year gastroenterology fellows, suggesting that some infrastructure for training programs may already be in place. In addition, continual performance evaluation of nonphysician endoscopists and guidelines for physician assistance would be needed for long-term viability of this practice

\section{Conclusion}

In conclusion, NPs present a viable option for delivering highquality screening colonoscopy. This, in turn, may help to reduce the overall health burden of CRC in the United States. 
Competing interests

Ms. Nandwani was on the Salix Pharmaceuticals Speakers Bureau.

References

[1] American Cancer Society. Cancer Facts \& Figures 2018. Atlanta, GA: American Cancer Society; 2018

[2] Kahi C], Pohl H, Myers L] et al. Colonoscopy and colorectal cancer mortality in the veterans affairs health care system: a case-control Study. Ann Intern Med 2018; 168: 481-488

[3] Nishihara R, Wu K, Lochhead P et al. Long-term colorectal-cancer incidence and mortality after lower endoscopy. N Engl J Med 2013; 369 : 1095-1105

[4] Zauber AG, Winawer S], O'Brien MJ et al. Colonoscopy polypectomy and long-term prevention of colorectal-cancer deaths. N Engl J Med 2012; 366: 687-696

[5] Joseph DA, Meester RG, Zauber AG et al. Colorectal cancer screening: estimated future colonoscopy need and current volume capacity. Cancer 2016; 122: 2479-2486

[6] Vijan S, Inadomi J, Hayward RA et al. Projections of demand and capacity for colonoscopy related to increasing rates of colorectal cancer screening in the United States. Aliment Pharmacol Ther 2004; 20: 507-515

[7] Dall T, Sen M, Zhang Y et al. The impact of improved colorectal cancer screening rates on adequacy of future supply of gastroenterologists. The Lewin Group; 2009: 1-33 Available from: https://www.olympusamerica.com/corporate/docs/Lewin-Gastroenterologist-Report.pdf

[8] Brown ML, Klabunde CN, Mysliwiec P. Current capacity for endoscopic colorectal cancer screening in the United States: data from the National Cancer Institute survey of colorectal cancer screening practices. Am Journal Med 2003; 115: 129-133

[9] U.S. Department of Health and Human Services, Health Resources and Services Administration, National Center for Health Workforce Analysis. Supply and Demand Projections for Internal Medicine Subspecialties: 2013-2025. Rockville, Maryland: 2016: Available from: https://bhw.hrsa.gov/sites/default/files/bhw/health-workforce-analysis/research/projections/internal-medicine-subspecialty-report.pdf

[10] Department of Health and Human Services/Centers for Medicare \& Medicaid Services. National Health Expenditures 2017 Highlights. 2019: Available from: https://www.cms.gov/Research-StatisticsData-and-Systems/Statistics-Trends-and-Reports/NationalHealthExpendData/Downloads/highlights.pdf

[11] McClellan MB, Leavitt MO. Competencies and tools to shift payments from volume to value. JAMA 2016; 316: 1655-1656

[12] Steinwachs D, Allen JD, Barlow WE et al. NIH state-of-the-science conference statement: enhancing the use and quality of colorectal cancer screening. NIH Consens State Sci Statements 2010; 27: 1-31

[13] Schoenfeld P, Piorkowski M, Allaire J et al. Flexible sigmoidoscopy by nurses: state of the art 1999. Gastroenterol Nurs 1999; 22: 254-261

[14] Day LW, Siao D, Inadomi JM et al. Non-physicians performing lower and upper endoscopy: a systematic review and meta-analysis. Endoscopy 2014; 46: 401-410

[15] Ikenberry SO, Anderson MA, Banerjee $S$ et al. Endoscopy by nonphysicians. Gastrointest Endosc 2009; 69: 767-770

[16] Faigel DO, Baron TH, Lewis B et al. Ensuring competence in endoscopy. ASGE Pres [Internet] 2006: 1-32 https://www.asge.org/docs/ default-source/education/practice_guidelines/doc-competence.pdf? sfvrsn $=6$
[17] Rex DK, Petrini JL, Baron TH et al. Quality indicators for colonoscopy. Am J Gastroenterol 2006; 101: 873-885

[18] Rex D, Cohen J, Pike IM et al. Quality indicators for colonoscopy. Gastrointest Endosc 2015; 81: 31-53

[19] Rex DK, Boland CR, Dominitz JA et al. Colorectal cancer screening: recommendations for physicians and patients from the U.S. MultiSociety Task Force on colorectal cancer. Am J Gastroenterol 2017; 112: 1016-1030

[20] Harewood GC, Lieberman DA. Colonoscopy practice patterns since introduction of medicare coverage for average-risk screening. Clin Gastroenterol Hepatol 2004; 2: 72-77

[21] Dall T, Chakrabarti R, lacobucci W et al. The complexities of physician supply and demand 2017 update: projections from 2015 to 2030. Washington, DC: Association of American Medical Colleges; 2017

[22] Cram P, Inadomi J, Cowen ME et al. The impact of a healthy celebrity spokesperson on preventive health behavior: the Katie Couric effect. Arch Int Med 2003; 163: 1601-1605

[23] Elta GH. Gl training: where are we headed? Am J Gastroenterol 2011; 106: 395-397

[24] Carthon MB, Barnes H, Sarik DA. Federal policies influence access to primary care and nurse practitioner workforce. J Nurse Pract 2015; 11: $526-530$

[25] Newhouse RP, Stanik-Hutt J, White KM et al. Advanced practice nurse outcomes 1990-2008: a systematic review. Nurs Econ 2011; 29: 230250

[26] Miskovitz P. Colonoscopy, chapter 4. XX: InTech; 2011: ISBN: 978953-307-568-6, PDF ISBN 978-953-51-6466-1, Published 2011-08-29

[27] Vance $M$. The nurse colonoscopist- training and quality assurance. Gastroinest Endosc Clin N Am 2005; 15: 829-837

[28] British Society of Gastroenterology. Non-medical endoscopists. BSG Guidelines in Gastroenterology. 2005: 1-6 Available from: https:// www.bsg.org.uk/asset/BAD09C38-AB8A-4C00-ADBC336757130AB8/

[29] Pathmakanthan S, Murray I, Smith K et al. Nurse endoscopists in United Kingdom health care: a survey of prevalence, skills and attitudes. J Adv Nurs 2001; 36: 705-710

[30] Maslekar S, Hughes M, Gardiner A et al. Patient satisfaction with lower gastrointestinal endoscopy: doctors, nurse and nonmedical endoscopists. Colorectal Dis 2010; 12: 1033-1038

[31] Koornstra J, Corporaal S, Giezen-Beintema WM et al. Colonoscopy training for nurse endoscopists: a feasibility study. Gastrointest Endosc 2009; 69: 688-695

[32] van Putten PG, Ter Borg F, Adang RP et al. Nurse endoscopists perform colonoscopies according to the international standard and with high patient satisfaction. Endoscopy 2012; 44: 1127-1132

[33] Harriot M, Sandha G, Semlacher E et al. Nurse practitioner colonoscopy in colon cancer screening program: a novel and highly successful training and credentialing program in Canada [abstract]. DDW; 2012: Suppl A196

[34] Limoges-Gonzales M, Mann NS, Al-juburi A et al. Comparisons of screening colonoscopy performed by a nurse practitioner and gastroenterologists: a single-center randomized controlled trial. Gastroenterol Nurs 2011; 34: 210-216

[35] Riegert M, Khashab M, Kalloo A. Experience of a nurse practitioner performing colonoscopy at a tertiary center in the United States. J Gastrointest Dig Syst 2015; 5: 3

[36] Cole A, Jackson JE, Doescher M. Urban-rural disparities in colorectal cancer screening: cross-sectional analysis of 1998-2005 data from the Centers for Disease Control's Behavioral Risk Factor Surveillance Study. Cancer Med 2012; 1: 350-356 